\title{
Neck of the Pancreas
}

National Cancer Institute

\section{Source}

National Cancer Institute. Neck of the Pancreas. NCI Thesaurus. Code C158551.

The portion of the pancreas that is the junction of the head and body of the pancreas;

the portion of the pancreas that lies anterior to the aorta. 